\title{
Networks within networks: scaling response operations in the lightning complex fires in northern california, August 2020
}

\author{
Louise K. Comfort ${ }^{1 *}$ \\ ${ }^{1}$ Graduate School of Public and International Affairs University of Pittsburgh, Pittsburgh, PA 15260
}

\begin{abstract}
Wildfire risk has increased dramatically in California over more than two decades, 2000 2021, reflecting the intense impact of climate change on the state's environmental and ecological systems. Most urgent is the impact of wildfire at the wildland-urban-interface (WUI), and the challenge to prevent cascading disaster for regions connected via interdependent lifelines of transportation, communications, electrical power, water, sewer, and gas line distribution systems that characterize geographic regions. To what extent do large, multi-organizational, multi-jurisdictional networks of organizations learn from experience and adapt their performance in response to the dynamic conditions of an actual extreme event? This article identifies four types of networks operating in the 2020 Lightning Complex Wildfires in northern California and documents the rapid escalation of risk and costs based on a preliminary analysis of the 209 incident reports filed by California Department of Forestry and Fire Protection (CalFire) for the SCU Fire that engulfed large sections of five counties in the southeastern San Francisco Bay Region. The article concludes that Interagency Incident Management Networks provide essential intelligence to support local management of operations in the dynamic context of wildfire risk.
\end{abstract}

\section{Introduction}

\subsection{The Challenge: Managing catastrophic hazards.}

Dramatic shifts in weather patterns resulting from climate change have created more frequent and more extreme events that threaten the safety and well-being of communities across the world. Nowhere is this trend more evident than in California, USA, where drought conditions continuing over multiple years have extended wildfire season from typically dry summer months to virtually a year-round hazard, leading to catastrophic mega-wildfires [22]. Five of the 20 largest wildfires in California's history occurred within the year, 2020 [17], only to be followed by the 2021 record of 8,239 fires documented by October 2021. The largest, the Dixie Fire, ignited on July 13, 2021, consumed more than 963,000 acres, and was extinguished only by welcome rains on October 24, 2021, after burning for more than three months [24].

The dramatically altered landscape of wildfire risk in California has challenged in fundamental ways the organizational infrastructure designed for managing the rapidly changing threat of wildfire in a large state that is both ecologically and demographically diverse. While experience from previous years has demonstrated that the wildfire threat is multidisciplinary and requires a multiorganizational, multi-jurisdictional effort to mitigate the risk, the larger question is how to design and implement effective operations to respond to dynamic wildfire events in real time.

Recognizing mounting losses from the increasing frequency, scale, and scope of wildfire in the last decade, California has countered this threat by making significant investments in building capacity for mitigating wildfire risk through increased funding not only for equipment and personnel, but also for research, technologies, and training to increase 'organizational intelligence' in managing wildfire risk [3]. Doing so has extended responsibility for decision making to wider networks of public, private, and nonprofit organizations tasked with building resilience to wildfire risk statewide, but it raises a further question. How do operational networks learn, adapt, and change in response to potentially catastrophic events in a dynamic, diverse environment?

\subsection{Policy Issue:}

The question of how organizations adapt to rapidly changing, urgent conditions has drawn the attention of organizational theorists for decades (LaPorte and Consolini, 1991; Weick, 1993; Comfort, 1999; Moynihan, 2009; Berthod et al. 2016; Steelman et al., 2021) [16].

*Corresponding author: $\underline{\mathrm{kc} @ \text { pitt.edu }}$ 
Initially framed as the 'edge of chaos,' Kauffman (1993: 174) characterized this transition to innovative action as requiring "sufficient structure to hold and exchange information, but sufficient flexibility to adapt to changing conditions." From an early concept of "high reliability" organizations (Rochlin, 1987; Weick and Roberts, 1993) to a recognition of organizational structure as networks (Prietula and Carley, 1999; Comfort, 1999; Kapucu, 2006) to an emerging focus on networks undergoing change during operations (Moynihan, 2009; Berthod et al., 2016; Comfort and Zhang, 2020; Steelman et al., 2021), researchers have observed and documented organizational adaptation to changing environments. But the factors that both drive and limit organizational change, especially in networks of organizations that are mobilized for a massive, dynamic event, are not well understood, specifically under the urgent stress of escalating disaster. No single organization has the resources, personnel, equipment, and oversight to manage a catastrophic wildfire event alone. Necessarily these events are multiorganizational, multi-disciplinary, and interdependent. They require an innovative framework for managing mobilization, strategy development, and adaptive action in a dynamic field environment. These requirements exceed the capacity of most emergency response organizations, even when plans and training are in place. In California, the Standardized Emergency Management System (SEMS) is required training for all agencies engaged in emergency response operations (California Office of Emergency Services, 2015), but the size, scope, and scale of mega-wildfires strain the capacity of organizations even with advanced training and major investment in resources and personnel.

\subsection{Collective investment in change.}

After experiencing devastating fires in which the demand exceeded the investments made in 2019, the 2020 California state budget increased that investment to augment the number of personnel, helicopters, advanced training in anticipation of fires as the drought continued in 2020. The assumption underlying this investment is that the network of organizations tasked with responsibility for managing wildfire risk statewide would learn, incorporate new technologies for decision support into improved practice, and build collaborative relationships among multiple jurisdictions, disciplines, organizations, and communities to create an innovative approach for managing wildfire risk for the entire state. The state further relies on the Emergency Mutual Assistance Compact (EMAC) (U.S. Congress, PL 104$321,1996)$ that enables one state afflicted by a serious hazard to request assistance from neighboring states, with the caveat that the receiving state would reciprocate in kind when neighboring states needed assistance. Wildfire risk, of course, does not stop at state boundaries. In the summer of 2020, all western states suffered extreme wildfire events - Washington, Oregon, Idaho, Nevada, Colorado, and Arizona - to the extent that neighboring states could not respond to most of California's requests for assistance as their resources were needed urgently to respond to wildfire outbreaks at home (Morris and Dennis, 2021: p.21). The scale and scope of wildfires in the region increased the urgency for response networks in California to learn to adapt quickly in their own context. Inquiry into networks as learning mechanisms. To what extent do large, multi-organizational, multi-jurisdictional networks of organizations learn from experience and adapt their performance in response to the dynamic conditions of an actual event? If so, what

factors contribute to network learning in large-scale, mega-disasters? Conversely, what factors inhibit the capacity of networks to adapt their performance in large, diverse, dynamic contexts of operations? These questions are particularly relevant for public policy and administrative theory in California in reference to wildfire risk. With a GDP of $\$ 3.2$ trillion, California ranks as the largest economy of all 50 US states and as the fifth largest economy in the world, after Germany but ahead of India (Hughes, 2020). Maintaining that economic ranking depends on the capacity of the state to manage wildfire risk, while also maintaining the environmental resources of the state that generate economic productivity and wellbeing for its population.

The capacity for networks to learn returns to the earlier framing of the question in organizational theory, and the first task is to define what constitutes "sufficient structure to hold and exchange information" among the large number of organizations and jurisdictions involved in response operations in wildfire events. The second task, equally critical, is to define what is "sufficient flexibility to adapt to changing conditions" in an actual wildfire event. The inherent tension between structure and flexibility in organizational response networks is clear but needs to be redefined in the context of actual practice. Learning to calibrate organizational structure to the demand for flexibility in adapting to dynamic situations in a functional operational system is a primary challenge. In a large, diverse, multiorganizational response system, the calibration depends upon the communication flow within and between different types of networks engaged in response operations. Specifically, it means identifying the type of intelligence that is needed by emergency responders to adapt their actions to a changing operational environment, the validity and timing of that intelligence as it is shared within and between networks in the larger operational system, and the level of prior knowledge and training among a diverse group of participants to comprehend the intelligence quickly when it is shared.

\subsection{Research questions:}

To address specifically the challenge of calibrating structure to flexibility in practice, this paper examines networks as the primary unit of analysis in organizational response operations and focuses on four questions that explore the potential and limits of network learning in the context of actual wildfire events. The questions include:

1. What types of networks can be identified in practice in managing wildfire risk, and what role does each network play in a larger wildfire response system? 
2. What factors - social and technical -- facilitate adaptive performance to changing conditions among the networks?

3. What factors - social and technical -- hinder adaptive performance to changing conditions among networks?

4. What factors operate to calibrate structure to capacity for flexibility in forging a functional operating system for managing wildfire risk?

This paper will examine these questions in the context of actual wildfire operations that occurred on the same day, August 17, 2020, in northern California largely within the San Francisco Bay Area's Metropolitan Region of nine counties, 101 cities, and 7 million residents (www.bayareacensus.ca.gov). These events were triggered by a rare, meteorological phenomenon of an intense shower of dry lightning strikes over a 24-hour period that ignited simultaneous fires in parched grasslands and wooded areas with dead trees damaged by a years-long drought. The characteristics of the wildfire events are given more detail in section 3 below. Specifically, the paper will focus on the SCU Complex Fire in the southern counties of the San Francisco Bay Area, although the full analysis in progress will address all three fires, assessing the regional impact of simultaneous fires.

The paper proceeds as follows. The next section reviews briefly the types of organizational networks relevant to the evolution of network learning. The third section describes the context of the 2020 Lightning Complex Fires that created an extraordinarily challenging environment for organizational response operations in dynamic wildfire events. The fourth section will report the data sources, collection, and methods of analysis. The fifth section will present findings, and the final section will summarize the conclusions of the study and suggest next steps for further analysis.

\subsection{Theoretical Framework of Network Learning Processes}

Networks have long been studied as organizational systems that form in response to urgent events. Early studies largely focused on identifying the structure of organizations engaged in response operations in past events, tracing the interactions among participating organizations, and estimating their positions of influence within the larger response system (Kapucu, 2006; Agranoff, 2007; Moynihan, 2009; Butts, 2009; Hu et al., 2015). These analyses distinguished between planned networks designed to perform specific services in emergency response operations, for example, the Incident Command System adopted among California fire departments in the late 1970's (Jensen, 2016; Nowell and Steelman, 2019) and emergent networks of volunteers who assist in recovery following community disasters (Drabek, 1981; 1985; Comfort and Zhang, 2020). The early studies established networks as primary organizational structures capable of performing complex operations embedded within larger social systems. More recent analyses of networks have focused on the processes of network adaptation in dynamic, urgent events (Carley et al., 2016; Comfort, 2019; Steelman et al., 2021).

\subsubsection{Sociotechnical Networks}

Recent years have seen positive change in network performance due to the integration of emerging information technologies into planned network structures for mitigation and response operations. Such networks function reasonably well for moderate events that remain within the bounds of known resources, skills, knowledge of responsibility and functions in social performance. They use technologies to increase the search, exchange, and updating of information to enhance collective cognition of risk and build the coherence needed for collective action under threat (Comfort, 2007; Comfort et al., 2020; Comfort and Rhodes, in press, 2022).

\subsubsection{Operational Networks}

Mobilizing operations in an actual field event involves adaptation to the local context and including local personnel and emergent groups of volunteers into structured response actions. This task means providing sufficient guidance to local personnel to enable them to provide valid information regarding local conditions, disrupted by disaster degradation and destruction, coupled with sufficient flexibility to allow the formal organizations to adapt their performance accordingly. Operational networks merge the structure of planned networks with the local knowledge of emergent networks to adjust the performance of the expanding response system dynamically as operational conditions vary. This form of adaptation relies on rapid, timely search and exchange of information between incoming response personnel and local volunteers who have knowledge and experience of local conditions (Comfort and Zhang, 2020).

\subsubsection{Intelligence Networks}

The fundamental challenge posed by wildfire risk in California and other states and countries lies in the sobering potential for catastrophe; that is, when the demands posed by actual hazard events exceed the scope and scale of planned operations that are constrained by tight time requirements for urgent response, limited resources and skills, and unanticipated demands for interdisciplinary knowledge. These limitations lead to high costs in loss of lives, property, livelihoods, and cascading events. Such demands overwhelm the existing operating capacity of organizational networks in emergency response operations and require a fundamental reconceptualization of the phenomena of hazard emergence, mitigation, preparedness, response, and recovery strategies. In these rapidly escalating conditions, intelligence networks become a primary resource in managing an urgent event, bringing it under control more quickly while minimizing the damage. These networks are essentially 'advice networks' (Kilduff 
and Krackhardt, 2008) as they do not replace existing operational personnel, but rather complement and supplement their authority to conduct field operations. Intelligence networks bring personnel with more experience, specialized knowledge, and fresh concepts in organizational performance to provide welcome back-up support to the management of operational personnel in extreme events.

\subsubsection{Realigning Scale, Scope, and Time in Network Performance.}

The relationships among people, jurisdictions, organizations/institutions, technologies, and risk need to be redesigned as functional networks capable of learning, redesign, and recalibration both in reciprocal response to participating actors and to the physical environment in which they operate. An initial effort to re-imagine functional networks might include systematic efforts to design sets of networks that can realign the scale, scope, and timing of their operations to fit the demands of the environment in which they are operating. The added capacity of the sub-nets to gain a systems view through visualization of operations could be provided through innovative technology in near-real time.

\subsection{The Lightning Complex Fires in Northern California, August 2020.}

\subsubsection{The Context}

On August 17, 2020, seven major wildfires were ignited in northern California by a singular meteorological event, dry lightning strikes in hot, parched grasslands and forests with trees dying from prolonged drought. More than 12,000 lightning strikes in highly combustible wildlands were recorded over two days, August 17-18, 2020, throughout northern California (CalFire, Incident Reports, 2020). Three of the largest wildfires were burning simultaneously in eight of the nine counties in the San Francisco Metropolitan Bay Area, home to seven million residents. Only the small, urban county of San Francisco escaped the wildfires.

The SCU Complex Fire spread over the three southern counties - Santa Clara, Alameda, Contra Costa and stretched over to adjacent San Joaquin and Stanislaus Counties - burning 396,622 acres and destroying 222 structures. The LNU Complex fire ignited in the northern counties of Solano, Napa, and Sonoma, spreading north to Lake County and east to Yolo County, burning 363,220 acres and destroying a larger number of structures, 1491, in a more populated area. The CZU Complex Fire ignited in San Mateo County and adjacent Santa Cruz County, destroying old growth sequoias in Big Trees State Park, and threatening the University of California, Santa Cruz campus. The next day, August 18, the Woodward Fire ignited in Marin County, burning a smaller acreage but distracting attention and resources from the larger fires burning in more heavily populated areas.

\subsubsection{The Challenge}

The demands for response, coordination, and control in this set of actual events were unimaginably complex under urgent threat. The California Department of Forestry and Fire Protection (CalFire), the public agency with legal responsibility for managing wildfire risk, faced an excruciatingly difficult set of interrelated and escalating tasks in leading and organizing coherent response operations to an ever-shifting dynamic of field conditions. The only approach that appeared possible was to activate simultaneously a network of networks in response operations. Yet, doing so across multiple jurisdictions that had widely varying access to resources and were constrained by health restrictions imposed by the COVID-19 pandemic presented a formidable challenge to agency personnel.

In this context, CalFire adopted a management strategy that had its origins in military operations but was adapted to the rapidly changing operational environments of extreme events. CalFire formed Interagency Incident Management Teams (IMTs) composed of experienced managers from different jurisdictions and disciplinary backgrounds with knowledge and access to resources relevant to wildfire ignition and control (Situation Reports, CalFire, 2020). A primary function of these teams is to collect, synthesize, and analyze information from multiple sources to inform action strategies for operational teams and to support the implementation of these strategies in field operations. The rationale for mobilizing these teams, especially in wildfire situations, is that timely, informed action at the local level brings the overall incident under control more quickly and more effectively, saving lives, property, and reducing overall losses. Personnel included in the IIMTs bridged organizational, jurisdictional, and disciplinary boundaries to create a systems perspective for managing the wildfire and to provide hazard intelligence and complementary analytical support to the local Incident Commander and his/her team. Importantly, the IIMTs did not replace the local Incident Command Teams, but rather acknowledged the extraordinary burden they were facing and provided an advanced level of hazard intelligence, analysis, experience, and informed access to external support for aid in coping with rapidly escalating wildfires.

\section{Methods and Data.}

\subsection{Methods}

The method most appropriate for this complex policy problem of managing mega-wildfire is to conduct an initial exploratory case study of actual events (Yin, 2016). The first task is to identify the networks that were engaged in field operations in response to the fires. Four types of networks were likely involved in response operations for each of the fire incidents, the LNU, SCU, and CZU Complex Fires. These types are: 1) planned networks that represent the formal organizational structure of the Standardized Emergency Response System (SEMS) in which all California emergency response personnel are 
trained; 2) emergent networks of local organizations and volunteers that responded spontaneously to each of the three fires; 3 ) operational networks that integrated the first two types - planned and emergent - into reasonably coherent operational networks led by CalFire; and 4) Interagency Incident Management Teams, teams of experienced personnel from federal, state, regional, and county agencies that brought advanced skills and knowledge to support local personnel in coordinating operations that involved mobilizing resources from multiple agencies, organizations, and jurisdictions under critical time constraints. This preliminary study will focus on the SCU Complex Fire in the southern counties of the San Francisco Bay Region.

\subsection{Data}

Access to incident data needed to distinguish the four types of networks is not easily available. Presumably, all data pertaining to wildfire operations are public and available to interested parties. In practice, incident data are held by operational agencies and are not readily released. It is possible to file a Public Records Request and specify the data one wishes to access and the reason for study, which I have done. However, the NFIRS (National Fire Incident Reporting System) data for these lightning fires is not yet available in Fall 2021, but perhaps 2022. The second option is to review all agency reports and press briefings that provide general information about the size, scale, and duration of operations, but lack specific identification of agencies, jurisdictions, private or nonprofit organizations that were involved in response operations. The third alternative is to review news reports of operations that would provide some information about community organizations as well as public agencies, but that are likely not complete. This initial exploratory study is based on data sources that are publicly available, including public reports, plans, and official briefings from CalFire and the Governor's Office of Emergency Services, State of California.

\subsubsection{Data analysis}

The types of investments made in preparing for the 2020 fire season can be identified from the Governor's Strike Force Report published in March 2019. These investments can be verified by the reports of new equipment purchased, number of additional personnel hired and trained, and collaborative agreements with private companies and research organizations reported in the 2020 incident action reports filed by public agencies. While these data do not specifically identify the actual networks engaged in response operations in the lightning complex fires, they do verify the types of networks that were operating and at least the number of official personnel involved in the agency networks. These reports can be used to identify the basic parameters for a system dynamics model of information flowing through the types of active networks engaged in wildfire response operations that would characterize a learning system. This model will be developed in the next stage of research.

\subsection{Process Tracing}

Given the constraints on access to public data, the most appropriate method at this stage of research is systematic use of process tracing (Bennett and Checkel, 2014). Process tracing is defined as the logical construction of an explanatory narrative for the confirmation of different types of networks and their roles not only in response operations, but also in reshaping the basic understanding of public action in response to the burgeoning threat of wildfire and related hazards stemming from climate change. This method acknowledges that the data are incomplete, but the resulting narrative, based on the most complete data available, will be used to structure the next phase of analysis on networks of learning and adaptation in anticipation of catastrophic risk environments. Process tracing assumes that research on complex, uncertain events is an iterative process and that an important outcome is to prepare an informed basis for the next stage of rigorous analysis.

\section{Scaled Networks in Catastrophic Events?}

Previous research has documented extensively the operation of networks in emergency response (Hu, Khosa, and Kapucu, 2015). These networks have been identified both as planned and emergent networks. Yet, any planned network needs to adapt to the operational environment in which it works, and emergent networks that provide local knowledge assist with that adaptation. Skillful leadership in both planned and emergent networks, supported by timely information from the changing hazard environment, enables the mobilization of operational networks to manage hazards within known limits of time, knowledge, skills, and resources. Large-scale, catastrophic hazards require a different order of experience and innovation, and specialized teams of Interagency Incident Management Experts dispatched to different areas of need strengthen the whole system by providing expert support at vulnerable points of performance.

In effect, in large-scale, extreme events, the operational system expands, with multiple networks serving different functions and adjusting operations to the scope and scale of the event. A systems perspective is essential to mobilize resources in knowledge, skills, and experience to manage a larger, more dangerous, catastrophic event. In doing so, previous networks have generated the capacity to recognize the skills and resources they do not have but need to counter unexpected and unknown challenges as critical information becomes available and reveals possible alternative strategies for action. In environments of uncertainty, innovations in technology that monitor change in risk conditions in realtime are critical to maintaining a valid, current profile of risk that allows informed allocation of resources, skill, and time to mitigate potential damage and prevent cascading losses. 


\section{Preliminary Findings}

The figures below show the results from a preliminary analysis of the 209 incident reports filed by Cal Fire from the SCU Fire that engulfed large sections of Santa Clara, Alameda and Contra Costa Counties, spreading into sections of Stanislaus and San Joaquin Counties. While the fire was burning largely in wildlands bordering the metropolitan cities of Oakland and San Jose, the fires came dangerously close to threatening the electrical transmission center located outside San Jose that would have compromised the electrical grid for large parts of California and neighboring states. The strategic focus for wildfires at the wildland-urban-interface (WUI) is to prevent cascading disaster for regions connected through interdependent lifelines of electrical power, communications, transportation, water, wastewater, and gas distribution systems that characterize metropolitan regions. These interdependencies transform a wildfire event in close proximity to urban centers into a potentially catastrophic event affecting millions of people and shutting down economic and social activity for the region.

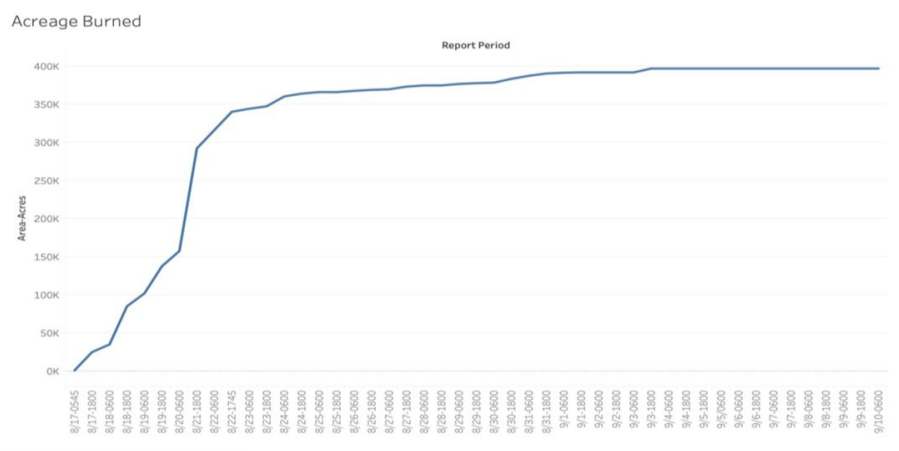

Fig. 1. Acreage burned as measured in 12-hour increments, SCU Lightning Complex Fire, 8-17-2020 to 9-10-2020.

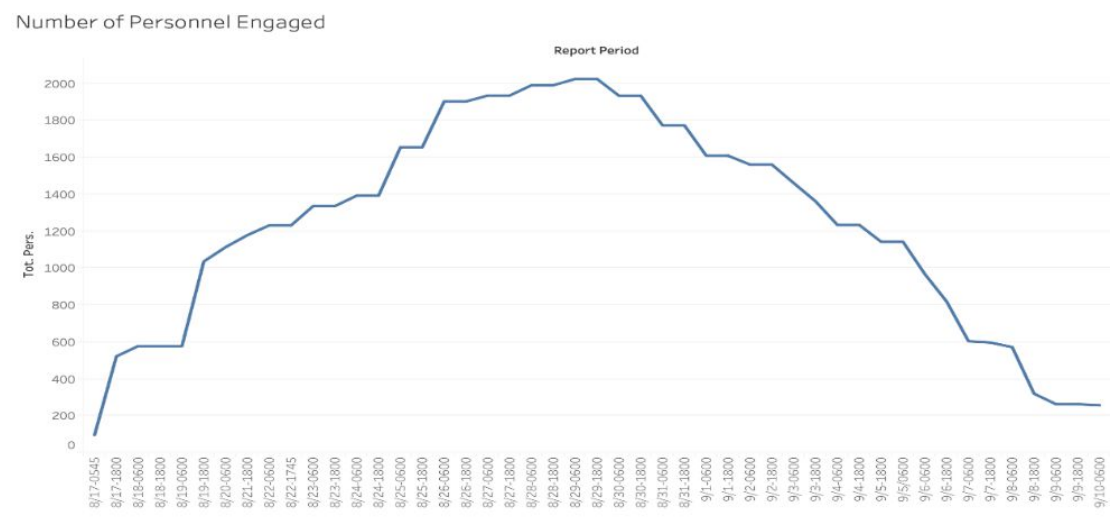

Fig. 2. Total personnel assigned to SCU Fire in 12-hour increments, 8-17-2020 - 9-10-2020.

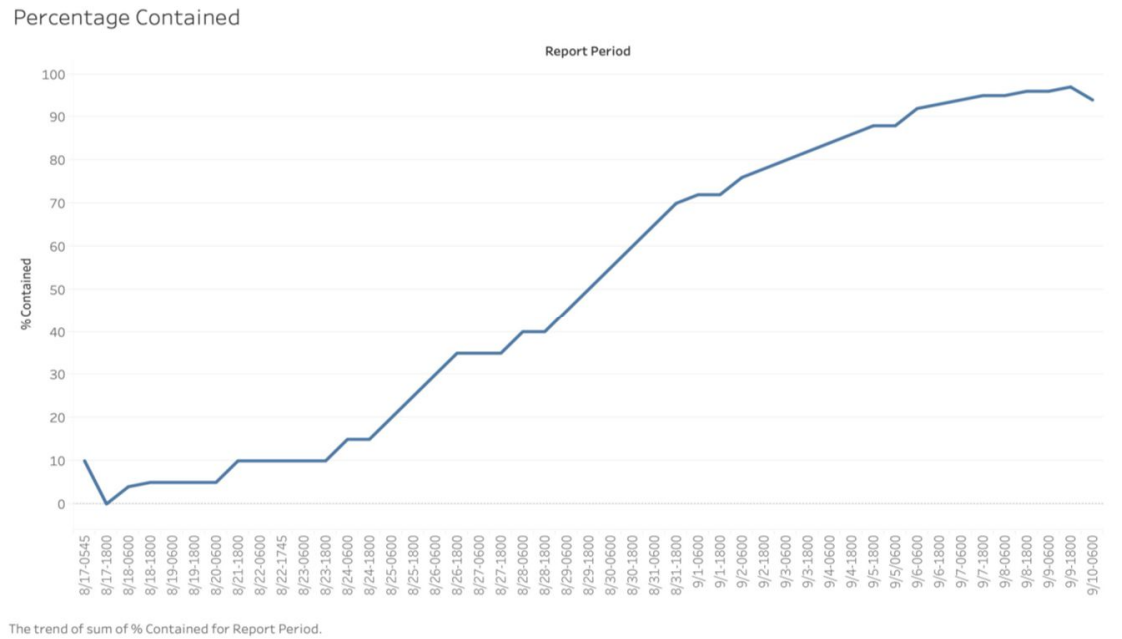

Fig. 3. Percent of SCU fire area contained by 12-hour increments, 8-17-2020 -9-10-2020. 


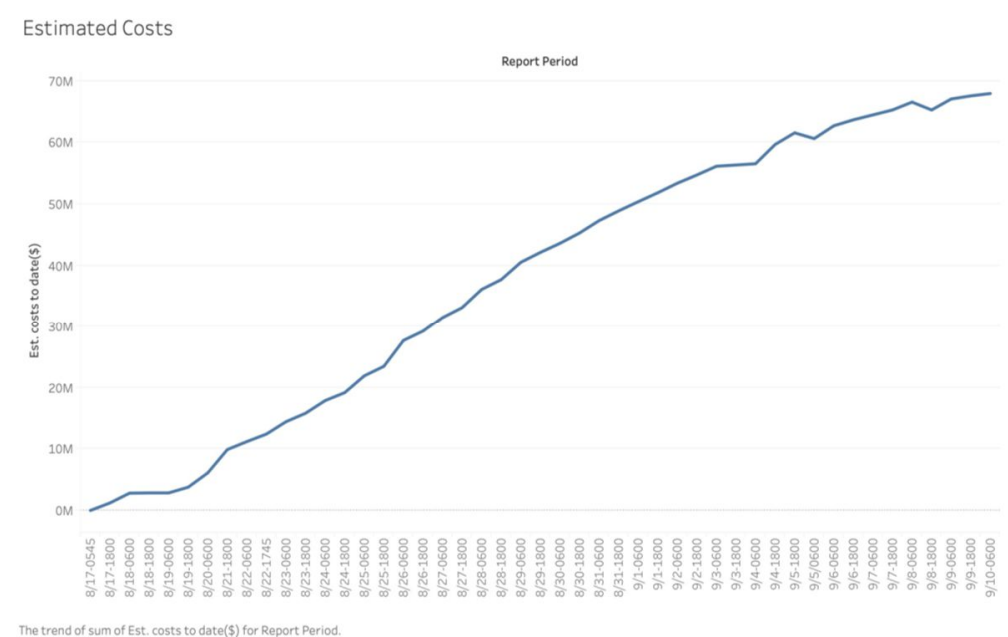

Fig. 4. Estimated costs for SCU Fire in millions of USD by 12-hour increments, 817-2020 - 9-10-2020.

As Fig. 1 illustrates, the fire escalated rapidly in the first three days, doubling in size of acreage burned by 12hour periods, reaching nearly 350,000 acres in four days. In contrast, Fig. 2 shows the constrained mobilization of fire personnel and equipment over that same period, reaching the peak of 2,000 personnel only on August 29, 12 days into the incident.

Fig. 3 confirms the impact of constrained mobilization of resources to show that only after $8 / 29 / 2020$ with full allocation of personnel and aerial equipment to fight the fire, did the percentage of contained area steadily increase to full containment 10 days later, 9-10-2020.

The final tally of costs of fire suppression in terms of personnel allocated and equipment deployed was approximately $\$ 70$ million. This tally did not include costs of economic disruption and social dislocation to the communities affected.

\section{Building Networks within Networks to Reduce Wildfire Risk?}

The central question driving the larger study has not yet been answered fully, but preliminary analysis of data from the SCU Fire indicates the direction of that response. As local, state, and federal agencies scrambled to mobilize resources to contain the fire, the number of acres burned doubled and tripled in just four days, 8-17-20 to 8-21-20, shown in Fig. 1. In contrast, it took 12 full days, 8-17-20 to $8-29-20$ to mount a fully equipped, operational response to the fire, see Fig. 2. Consequently, the delay in mobilization of resources and personnel, coupled with punishing natural conditions of continuing heat and dry winds, extended the duration of the fire for two more weeks to September 10, 2020, with expanding losses in acreage burned and mounting costs for the region, as shown in Fig. 3 and 4.

Importantly, CalFire and responding agencies adapted their strategies of fire suppression to daily changes in wind direction, temperature, humidity, and availability of resources. Yet, the sobering observation is that the massive mobilization of personnel and resources required to suppress the fire, with its consequent coordination and communication processes, was repeatedly challenged as the fire, driven by hot, strong winds, flared in new areas, and jumped firebreaks that had painstakingly been cut the day before. The detailed analysis of the four types of networks is still in progress, and the role of the Interactive Incident Management Team (IIMT) needs to be fully documented and explained, but this initial assessment reports the key role of this team in maintaining the balance between structure and flexibility in response operations to bring the fire ultimately under control (Morris and Dennis, 2021).

\section{Policy Recommendations}

The critical function of intelligence in managing these dynamic wildfires is demonstrated by the findings cited above from the 2020 SCU Fire. Throughout the summer and fall of 2020, the six IIMT units in California were deployed continuously, as fires ignited, burned, and threatened urban communities. In most instances, their deployment came after the fires had ignited and, given the conditions of high temperatures, dry fuel, and high winds, the operational tasks exceeded the capacity of the available teams deployed on the ground. Based on the documented experience from the SCU fire and other wildfires observed during the summer of 2020, I offer four policy recommendations:

1. Deploy IIMT units to specific regions of known wildfire risk to develop current assessments and strategic plans for minimizing risk before actual fires ignite.

2. Build a knowledge base of conditions in WUI areas that include current states of risk and types of resources available to minimize that risk

3. Invest in advanced communications infrastructure to facilitate the rapid exchange of information that enables collective action to reduce risk

4. Provide clear, easy access to the WUI knowledge base to inform both operational personnel and community organizations committed to wildfire mitigation 
5. Engage community residents in systematic efforts to explore, comprehend, and build a sustainable future for communities at risk.

In practice, the State of California is already taking steps to build on the extraordinary events of the Lightning Complex Fires of 2020. For example, the University of California has organized a wildfire symposium to bring together researchers from all ten campuses to focus on the multidisciplinary aspects of wildfire and the conditions that contribute to long-term hazard and risk. This symposium also includes public agencies, private companies and nonprofit organizations that are engaged in activities to reduce wildfire risk. In effect, the University of California, a public research university with a mission of public service, is defining a distinct role for providing organizational intelligence for wildfire risk reduction. The University is taking an active role in collecting, aggregating, supporting, and sharing current, state-of-the-art research on wildfire risk with the broader population of California and in translating research findings into practical applications that can be adopted by organizations, communities, and households to reduce wildfire risk. The University of California system, already a network, is focusing attention and resources on a shared problem for the entire state and using these resources to bolster the capacity of public agencies to cope with a large-scale, long-term problem of wildfire risk.

Yet, the scale and severity of the dynamics of climate change driving wildfire risk in California require a statewide commitment from the broad array of public, private and nonprofit organizations and institutions to build a resilient approach to managing wildfire. Only by continuous, sustained, purposeful design and strategic action will California mitigate escalating wildfire risk.

I acknowledge, with thanks and appreciation, the Center for Information Technology Research in the Interest of Society (CITRIS), University of California, Berkeley, and my colleagues, Kenichi Soga, Bingyu Zhao, and Camille Crittenden for their thoughtful insights on the complex, interdisciplinary problem of wildfire management. I thank the CalFire Research and Development Program for assistance in gaining access to the 209 Incident Reports.

\section{References.}

1. Berthod, O.G. Hammer, Michael; M. Seitz, Gordon; Raab, Jörg; Sydow, Jörg. From High-Reliability Organizations to High-Reliability Networks: The Dynamics of Network Governance in the Face of Emergency. Journal of Public Administration Research and Theory, 352-371. . (2017)

2. Butts, $\mathrm{T}$ Carter. Revisiting the Foundations of Network Analysis. SCIENCE. 325, 5939, 414-416 (2009)

3. California Governor's Office of Emergency Services. Cal OES Yellow Book: California Emergency Services Act, California Disaster Assistance Act, Emergency Compacts, California Disaster and Civil Defense Master Mutual Aid Agreement. Sacramento,CA,https://www.caloes.ca.gov/LegalAff
airsSite/Documents/Cal\%20OES\%20Yellow\%20Bo ok.pdf. (2015)

4. L.K Comfort. The Dynamics of Risk: Changing Technologies and Collective Action in Seismic Events. Princeton: Princeton University Press, Studies in Complexity. (2019)

5. Comfort, L.K., T.W. Haase, G. Ertan, and S.R. Scheinert. The Dynamics of Change Following Extreme Events: Transition, Scale, and Adaptation in Systems Under Stress. Administration \& Society (2019)

6. L.K. Comfort, N. Kapucu, K. Ko, S. Menoni, M. Siciliano. Crisis Decision-Making on a Global Scale: Transition from Cognition to Collective Action under Threat of COVID-19. Public Administration Review, 80, 4, 616-622 (2020)

7. L.K. Comfort, H. Zhang.. Operational Networks: Adaptation to Extreme Events in China. Risk Analysis (2020)

8. L.K Comfort,. M.L. Rhodes. Collective Cognition in Complex Systems, Chapter 2. In L.K. Comfort, and M.L. Rhodes. Global Risk Management: The Role of Cognition in Response to COVID-19. Routledge Press, (In production, March release) (2022)

9. Drabek, T. E.. Managing multiorganizational emergency responses: Emergent search and rescue networks in natural disaster and remote area settings. Boulder, CO: Institute of Behavioral Science, University of Colorado (1981)

10. T.E. Drabek, Managing the emergency response. Public Administration Review, 85-92 (1985)

11. J Gibb, A. Sune, S. Albers, 'Network learning: Episodes of interorganizational learning towards a collective performance goal'. European Management Journal, 35, 15-25 (2017).

12. $\mathrm{Hu}, \mathrm{Q}, \mathrm{S}$. Khosa, N. Kapucu. The intellectual structure of empirical social network research in public administration. Journal of Public Administration Research and Theory, 26 (4), 593561 (2015)

13. Hughes, A. Ryan If California Were a Country. Bull Oak Capital. https://bulloakcapital.com/blog/ifcalifornia-were-a-country/ July 27 (2020)

14. N. Kapucu. Interagency communication network during emergencies: Boundary spanners in multiagency coordination. American Review of Public Administration, 36 (2), 207-225 (2006)

15. L. Knight, 'Network learning: Exploring learning by interorganizational networks'. Human Relations, 55, 427-454 (2002)

16. Moynihan, D. The network governance of crisis response: Case studies of incident command system. Journal of Public Administration Research and Theory, 19 (4), 895-915 (2009)

17. Morris, George III, C. Dennis.. The 2020 Fire Siege. Sacramento: California Department of Fire and Forestry Protection (Cal Fire) (2021)

18. B. Nowell,T. Steelman, Communication under fire: The role of embeddedness in the emergence and efficacy of disaster response communication networks. Journal of Public Administration Research and Theory, 25 (3), 929-952 (2015). 
19. Nowell, Branda, T. Steelman.. Beyond ICS: How Should We Govern Complex Disasters in the United States? Journal of Homeland Security and Emergency Management. 16 (2), 2018-0067 (2019)

20. Office of the Governor, State of California.. Wildfires and Climate Change:California's Energy Future. Sacramento, CA: Governor Newsom's Strike Force Report. April (2019)

21. Provan, G. Keith, H.B. Milward.. A Preliminary Theory of Interorganizational Network Effectiveness: A Comparative Study of Four Community Mental Health Systems. Administrative Science Quarterly. 40 (1), 1-33 (1995)
22. Task Force, State of California.. California's Wildfire and Forest Resilience Action Plan. Sacramento, CA: Public Affairs Office, Department of Water Resources (2021)

23. U.S. Congress. Emergency Mutual Assistance Compact (EMAC), Public Law 104-321. Washington, DC: $104^{\text {th }}$ Congress. 110 Stat. 3877 (1996)

24. Vera, Vicente, Dixie Fire contained after burning more than 963,000 acres. ABC News. October 25. https:/www.abc10.com/article/news/local/wildfire/d ixie-fire-100-percent-contained/103-d2fd56f5-ca874bdb-8db9-68eecaa371e4 (2021) 